\title{
Risk factors of Osteoarthritis Knee - A Cross-sectional study
}

\author{
Pushpa S Patil ${ }^{1}$, Umesh R Dixit ${ }^{2}$, Chidendra M Shettar ${ }^{3}$ \\ ${ }^{1,2}$ Department of Community Medicine, ${ }^{3}$ Department of Orthopaedics, SDM College of Medical Sciences and \\ Hospital,Dharwad, India
}

\begin{abstract}
A hospital based cross sectional study was carried out in a tertiary care centre to study the risk factors of Osteoarthritis of Knee among patients attending Orthopaedics OPD. All patients aged between 40 and 65 years were included in the study. A total of 102 patients for a period of four months were studied. Nearly two thirds of our study subjects were women. OA increased with age and BMI. Risk factors like family history, history of knee injury and occupational knee bending were seen in only few of our study subjects. There is need to spread awareness among people to adopt preventive measures at an earlier age along with healthy lifestyle to reduce the body weight and hence the risk of $O A$.
\end{abstract}

Keywords: Age, BMI, Osteoarthritis, occupational knee bending, risk factors,.

\section{Introduction}

Osteoarthritis $(\mathrm{OA})$ is a chronic degenerative joint disease and is the commonest form of arthritis. It progresses slowly with usual signs and symptoms being pain, enlarged and deformed joints as well as limitation of the range of motion. It is also a leading cause of disability affecting $60-70 \%$ of the population older than 60 years. It usually affects the hand and large weight bearing joints, often the knee and the hip ${ }^{1}$.

The worldwide prevalence estimate for symptomatic OA is $9.6 \%$ among men and $18 \%$ among women ${ }^{2}$. It is the fourth leading cause of year lived with disability (YLD). It accounts for the decrease in activities of daily living (ADL) in elderly dependent population in the community ${ }^{3}$.

Indisputably the risk factors in high risk population include female gender, old age, overweight, history of previous injuries or surgeries on the knee ${ }^{4,5,6}$. Among females, the prevalence of OA is said to increase during menopausal age. Many studies have shown that loss of oestrogen at the time of menopause increases the women's risk of getting osteoarthritis? ${ }^{7}$. Although OA occurs all over the world, the prevalence and the pattern of the disease vary depending on the geographical distribution which in turn can provide valuable clues about the potential etiological factors. A hospital based study was carried out with a purpose to assess the sociodemographic and risk factors of OA among the study population.

\section{Materials and Methods:}

A hospital based cross sectional study was carried out for a period of four months from July 2012 to October 2012 at SDM College of Medical Sciences and Hospital, Dharwad. All patients in the age group of 4065 years and confirmed both clinically and radiologically for OA attending SDM Orthopaedics OPD were included in the study. Patients below the age of 40 years and above the age of 65 years were not included in the study. Also the patients with recent trauma with considerable tissue damage, patients with terminal conditions, alcohol abuse, psychiatric disorder and previous/ planned arthroplasty were excluded from the study. After obtaining informed consent, study subjects were interviewed and data was recorded on a standardized predesigned and a pre-tested questionnaire. Questionnaire focussed on Socio-demographic profile and assessment of possible risk factors (age, family history, obesity, physical activity, occupational knee bending and knee injury). Measurements like height, weight and body mass index (BMI) were recorded. The results were analysed using SPSS software version 20. Chi square test, ratios and proportions were used.

\section{Results}

A total of one hundred and two subjects were enrolled in the study of whom $35(34.3 \%)$ were males and $67(65.7 \%)$ were females. Table no. 1 shows that majority of them, $26(25.5 \%)$ were in the age group of 55 - 59 years. Only a quarter of study subjects $26(25.5 \%)$ had positive family history of OA. Of these, men (37.1\%) had higher percentage of family history compared to women (19.4\%). This difference was not statistically significant $\left(\chi^{2}=3.81\right.$ at $\mathrm{df}=1$ and $\left.\mathrm{p}>0.05\right)$. Most of the women $55(82.1 \%)$ were homemakers while majority of the men in the study $17(48.6 \%)$ were unskilled workers. Most of the study subjects 96 (94.2\%) belonged to Hindu religion. 76 (74.5\%) of the study subjects were literates. Most of them belonged to nuclear type of family $65(63.7 \%)$.

Table 2 shows the distribution of risk factors among study subjects. It was observed that majority of the study subjects, 57 (55.9\%) were obese. Obesity was more common amongst women 45 (67.2\%) compared to 
men 18 (51.4\%), who were more overweight. This difference was statistically significant at $\mathrm{p}<0.01\left(\chi^{2}=11.38\right.$ at $\mathrm{df}=2$ ).

Table 2 also shows that more than four fifth of the study subjects $82(80.4 \%)$ were involved in moderate level of physical activity. It was observed in the study that occupational knee bending was more commonly present in men. This risk factor was present in two out of every five men while it was observed in less than a quarter of women. This difference was however not statistically significant.

History of knee injury is another important risk factor that was studied. It was seen that most of our study subjects $85(83.3 \%)$ had no history of knee injury. The history of knee injury was almost equally distributed among both the sexes.

Table no. 1: Socio-demographic profile of study subjects:

\begin{tabular}{|l|l|l|l|}
\hline \multirow{2}{*}{ Age (in years) } & \multicolumn{2}{|c|}{ Sex } & \multirow{2}{*}{ Total } \\
\cline { 2 - 3 } & \multicolumn{1}{|c|}{ Male } & Female & \\
\cline { 2 - 3 } & No $(\%)$ & No $(\%)$ & No (\%) \\
\hline $40-44$ & $1(2.9)$ & $5(7.5)$ & $6(5.9)$ \\
\hline $45-49$ & $4(11.4)$ & $13(19.4)$ & $17(16.7)$ \\
\hline $50-54$ & $8(22.9)$ & $12(17.9)$ & $20(19.6)$ \\
\hline $55-59$ & $9(25.7)$ & $17(25.4)$ & $26(25.5)$ \\
\hline$>/=60$ & $13(37.1)$ & $20(29.9)$ & $33(32.4)$ \\
\hline Family history & \multicolumn{3}{|l}{} \\
\hline Present & $13(37.1)$ & $13(19.4)$ & $26(25.5)$ \\
\hline Absent & $22(62.9)$ & $54(80.6)$ & $76(74.5)$ \\
\hline
\end{tabular}

Table 2: Distribution of Risk Factors vs. Sex of study subjects

\begin{tabular}{|l|l|l|l|}
\hline \multirow{2}{*}{ Body Mass Index } & \multicolumn{2}{|c|}{ Sex } & \multirow{2}{*}{ Total } \\
\cline { 2 - 3 } & \multicolumn{1}{|c|}{ Male } & Female & \\
\cline { 2 - 3 } & No (\%) & No (\%) & No (\%) \\
\hline Underweight & $1(2.9)$ & 0 & $1(1.0)$ \\
\hline Normal & $4(11.4)$ & $8(11.9)$ & $12(11.8)$ \\
\hline Overweight & $18(51.4)$ & $14(20.9)$ & $32(31.4)$ \\
\hline Obese & $12(34.3)$ & $45(67.2)$ & $57(55.9)$ \\
\hline Physical Activity \\
\hline Sedentary & $4(11.5)$ & $15(22.3)$ & $19(18.6)$ \\
\hline Moderate & $31(88.6)$ & $51(76.1)$ & $82(80.4)$ \\
\hline Strenuous & 0 & $1(1.5)$ & $1(1.0)$ \\
\hline Occupational Knee Bending \\
\hline Present & $14(40.0)$ & $16(23.9)$ & $30(29.4)$ \\
\hline Absent & $21(60.0)$ & $51(76.1)$ & $72(70.6)$ \\
\hline Knee Injury & $5(14.3)$ & $12(17.9)$ & $17(16.7)$ \\
\hline Present & $30(85.7)$ & $55(82.1)$ & $85(83.3)$ \\
\hline Absent
\end{tabular}

\section{Discussion}

In our study it was observed that the percentage of people with osteoarthritis increased as the age increases. This observation is similar to that in a study done in south Delhi ${ }^{8}$ and at other places, 10 .

OA was more in women compared to men in our study ( $65.7 \%$ vs. $34.3 \%$ respectively). This difference can be possibly due to the lack of physical activity, mobility, social issues especially in our region and higher prevalence of obesity among women in general. A study done by Iqbal MN et al also observed that OA was more in women (74\%) compared to men $(26 \%)^{11}$. A similar observation was also made in a study done by Sharma MK et $\mathrm{al}^{10}$ which was $70.1 \%$ vs $41.6 \%$.

In our study it was observed that men were less in number compared to women for any given age group. However this observation differs from that made in a study by Dr David T Felson et al. This study observed that before age of 50, men were affected more while after age of 50 years women were more affected $^{12}$.

Family history of OA was present in a few 26/102 (25.5\%) of our study subjects. A study by Mangat G et al also reported presence of family history in only few of their patients $41 / 300(13.7 \%)^{13}$. 
Majority of our study subjects 57/ 102 (55.9\%) were obese. Mean BMI was $28.44 \pm 8.68 \mathrm{kgm}^{-2}$. Mean BMI was also found to be high 28.09 plus-minus 4.43 in a study done by Mangat $\mathrm{G}$ et $\mathrm{al}^{13}$. Also a study done by Iqbal MN et al observed that mean BMI was high $29.43 \pm 7.84$ in OA cases ${ }^{11}$.

In our study most men had more occupational knee bending compared to women ( $40 \%$ vs. $23.9 \%)$ This can be due to the fact that most of the women in our study were homemakers. A study done by Cooper $\mathrm{C}$ et al found that occupational knee bending is a positive risk factor for development of OA knee. The odds of getting OA with increased occupational knee bending were significantly more than for those who had no knee bending. The odds ratio varied from 1.2 to 6.9 for different types of knee bending ${ }^{14}$.

In our study, history of knee injury preceding the OA was found in only 17/102 (16.7\%) study subjects. This was in contrast to the observations made by Trivedi et al who observed that knee injury was present in $63.3 \%$ in patients with OA. Their study also found that the odds of getting OA after knee injury are 4.54 times than without any knee injury ${ }^{15}$.

\section{Conclusion:}

$\mathrm{OA}$ is a major public health problem especially in people after the age of 50 years. In our study we observed that there is relationship between age, sex and BMI with OA. Family history, occupational knee bending and history of knee injury were less prevalent in our study. The number of people with OA increased as the age increased; hence it is likely that if preventive measures can be taken in the earlier age groups OA can be prevented.

\section{Acknowledgements:}

We would like to thank the doctors and the patients who cooperated with the data collection. We also thank our principal, Dr. J V Chowti for giving us an opportunity to carry out the study.

\section{References:}

[1] Nevitt MC, Felson DT, Lester Gayle. Osteoarthritis initiative - Protocol for Cohort Study. http://oai.epiucsf.org/datarelease/docs/StudyDesignProtocol.pdf last accessed on 2012-11-07

[2] Prevalence and pattern of symptomatic knee osteoarthritis in Nigeria-A community based study.

[3] Epidemiology of knee Osteoarthritis - Results from Framingham study.

[4] Felson DT, Zhang Y. An update on the epidemiology of knee and hip osteoarthritis with a view to prevention. Arthritis Rheum 1998;41(8):1343-55.

[5] Felson DT, Chaisson CE. Understanding the relationship between body weight and osteoarthritis. Baillieres Clin Rheum 1997;11(4):671-81.

[6] Oliveria SA, Felson DT, et al. Body weight, body mass index, and incident symptomaticosteoarthritis of the hand, hip, and knee. Epidemiology 1999;10(2):161-6.

[7] Generalized osteoarthritis is a hormonally mediated disease-1989.

[8] Salve H, Gupta V, Palanivel C, Yadav K, Singh B. Prevalence of Knee Osteoarthritis amongst preimenopausal women in an Urban Resettlement Colony in south Delhi. Ind J of Pub Health vol 54 (3):155-7

[9] Joshi K, Rajesh K, Avasthi A. Morbidity profile and its relationship with disability and psychological distress among elderly people in Northern India. Int J Epiodemiol 2003;32:978-87

[10] Sharma MK, Swami HM, Bhatia V. An epidemiological study of correlates of osteoarthritis in geriatric population of UT Chandigarh. Indian J Community Med 2007;32:1-3

[11] Iqbal MN, Haidri FR, Motiani B, Mannan A. Frequency of factors associated with knee osteoarthritis. J Pak Med Assoc 2011; 61 (8): $786-9$

[12] Felson DT et al. Osteoarthritis: New insights. Part 1: The Disease and its risk factors. http://annals.org/data/Journals/AIM/19967/0000605-200010170-00016.pdf Last Accessed on 21 November 2012.

[13] Mangat G; Balakrishnan C; Venkatachalam S; Joshi VR. Pattern of osteoarthritis (OA) in India : a hospital based study. J Ind Rheumatism Assoc 1995; 3(4): 125-8

[14] Cyrus Cooper, Tim McAlindon, David Coggon, Peter Egger, Paul Dieppe. Occupational activity and osteoarthritis of the knee. Annals of the Rheumatic Diseases 1994; 53: 90-93

[15] Trivedi J, Bala DV, Trivedi KN. Study of case control study of Osteoarthritis and associated risk factors. Gujarat Med J 2009; 64 (2):98-9 